\title{
Secular Trend in Portugal
}

\author{
Cristina Padez \\ Departamento de Antropologia, Universidade de Coimbra, 3000-056 Portugal \\ Telephone: 351239 829051, Fax: 351239 823491, E-mail: cpadez@antrop.uc.pt
}

KEYWORDS Secular Trend. Stature. Menarche. Social Change. Portugal

\begin{abstract}
This study of secular trend in Portugal has shown that a positive increment in height occurred in Portuguese 18year-old males between 1904 and 2000, and a secular trend in the age at menarche, towards an earliest age, also took place. Mean height increased $8.93 \mathrm{~cm}$, from 1904 to 2000, when reached 172,13 cm. Besides that, in 2000, statistically significant differences $(\mathrm{p} \leq 0.001)$ among the districts were found: males from Lisboa $(172.79 \mathrm{~cm})$ and Braga $(172.67 \mathrm{~cm})$, the most developed districts, are the tallest, and those from Madeira $(170.67 \mathrm{~cm})$, Castelo Branco, Leiria and Coimbra (171,31 $\mathrm{cm})$ are the shortest. A decrease in age at menarche was observed: girls born in the decade 1880-90 had a mean age at menarche of 15 years and those born in 1970-1980 had a mean age at menarche of 12.03 years. The increase in mean stature and the decrease in mean menarcheal age represent a general improvement in the living conditions that occurred in Portugal after the 1970s. The Portuguese nutritional pattern, the health care system, the economy and even in housing conditions changed between 1960 and 1997
\end{abstract}

\section{INTRODUCTION}

Since the end of the 19th century a positive secular trend towards a taller adult stature and an earliest age at menarche can be found in almost every country in Europe, North America and Japan. The most important environmental factors to influence secular trends are nutrition and health. Indirect factors affecting nutrition (both qualitatively and quantitatively) and health are alterations in socio-economic living conditions, social and health care (preventive and curative), minimum income, quality of food preparation, better sanitary conditions, mass vaccination, level of education (Tanner, 1992; Bodzsár and Susanne, 1998; Hauspie et al., 1996). Growth of a population can therefore be used as a "mirror of conditions in society" (Tanner, 1986).

Adult height reached a plateau during the mid1980s in some developed European countries, which suggest that they are possibly about to achieve their full genetic potential or that their social conditions have ceased to improve. In the European countries the secular trend is more marked amongst the lower social classes than in the upper ones (Chinn et al., 1989; Vercauteren, 1993).

During the past century, an earlier age at menarche has been observed in most European countries, though during the past few decades this effect has slowed or even halted. The mean age at menarche reached 12-13 years in the majority of developed populations and probably these populations reached a plateau (Keizer-
Schrama, 2001). The leveling off of menarcheal age in some countries is either the effect of a ceasing improvement of environmental factors, or of reaching the genetically determined limits of normality in menarcheal age Hauspie et al 1996. In almost all the developed populations, only birth order showed a significant effect on the mean age at menarche, with later born girls reporting a later age at menarche. The other socio-demographic characteristics namely, parents' educational level, size of the family and place of residence did not show any significant effect (Billewicz et al., 1981; Cameron and Nadgdee 1996; Sánchez-Andrés 1997; Apraiz, 1999).

The aim of the present study is examine how social and economic changes that took place in Portugal during the 20th century relate to changes in adult height in young males and in age at menarche. Regional differences, from 1904 to 2000, will also be analyzed in this large sample of Portuguese males.

\subsection{Social Changes in Portugal}

In contrast to many other European countries, that had important social and economic changes after World War II, the general improvement in the living conditions of the Portuguese population took place late during the 1960s. At that time, from the demographic point of view, Portugal was, at the begin of 1960, a very different country in Europe: it had the highest proportion of young people (less than 15 
years), the lowest proportion of old people (more than 65 years), the lowest life expectancy at birth, the highest rate of natality and the highest rate of infant mortality. After forty years, these values are very different. It is the country with the lowest population growth rate, and the proportion of young and old people are now similar to average European values that presented $18 \%$ and $15 \%$, respectively. Life expectancy at birth is still one of the lowest (70.3 for men and 77.5 years for women) but close to the average European values (74 years), the birth rate is similar to the European mean, and the infant mortality rate (10.8) is also similar to other European countries (9) (Barreto, 1996, 2000; PNUD, 2001).

However, there are some specific factors in the social and economic evolution of the Portuguese population. The first is the rate of emigration to Europe, especially to France, and the second one is the internal migration from the countryside to the cities, especially to Lisboa and Porto. In 1990 almost $40 \%$ of the Portuguese population live in the Lisboa and Porto areas (Barreto, 1996, 2000).

The industrial sector showed, also, an acceleration in the 1960s. But, in contrast to all the other European countries, services will be the more important economic sector and not industry.

An indirect consequence of these deep changes in social and economic structures was a global improvement of living conditions during the past forty years.

\section{MATERIALS AND METHODS}

For the analysis of secular trend in stature, data were obtained from the records of the medical examination at the District Recruiting Centers of Portugal (North, Center and South). Military service is compulsory in Portugal. The entire cohort of males born in a given year is examined by military physician's during the registration visit lasting three days. The sample can thus be regarded as representing all regions of the country and all the social strata.

The sample includes all the Portuguese 18year-old males born between 1966 and 1982 and examined between 1985 and 2000 (995101 subjects). Mean height values will be presented in a Table for those examined in 1985, 1990 and 2000 and the means for each year, from 1985 to 2000, will be presented in a Figure. Data published by Lacerda (1904) for all the districts of Portugal, also in 18-year-old conscripts and data published by Sobral (1980) for the years 1930 to 1980 just for the South of Portugal (Districts of Lisboa, Setúbal, Évora and Beja), also in conscripts, were also considered.

In the medical examination height was measured to the nearest $\mathrm{cm}$.

Localities of the subject's residence by Districts (i.e., administrative region) were also obtained. In Portugal there are 20 Districts. Two of them (Açores and Madeira) are islands located in the Atlantic Ocean.

For age at menarche data was collected between November 1990 and May 1991, in a cross-sectional anthropometric survey that was carried out in three secondary schools in Coimbra. A total of 516 girls, with a decimal age comprised between 9 and 19 years, were examined. For each girl, information about the date of examination, her date of birth, whether she had attained menarche and, if so, the date of that occurrence was recorded. Age at menarche was calculated by means of a probit analysis.

Vital Statistics: Data concerning demography, health, economy, nutrition and house conditions - 1920-1990 - were collected from the statistical yearbooks published by the National Institute of Statistics (INE). For same variables, e. g., house conditions, we just have data after 1960.

Data concerning total daily energy intake (calories/day) of some products, between 1963 and 1997, and the program of milk supply in elementary schools were also analyze.

\section{SOCIODEMOGRAPHIC AND HEALTH CHARACTERISTICS}

Table 1 summarizes the evolution of some socio-demographic and health system in Portugal during the 20th century. From 1920 to 1990 birth rate, the percentage of young people $(<15$ years), infant mortality rate as well as postneonatal mortality rate all showed a strong decrease in their values. And, at the same time, the percentage of old people, life expectancy in both sexes, and adult literacy increased.

The health system of Portugal showed, also, strong changes. Between 1960 and 1990, the number of physicians per 1000 population and the percentage of newborns that delivered at a hospital increased. On the other hand, maternal mortality decreased. 
In the economic sector the agricultural system decreased from $48.2 \%$ in 1930 to $10.6 \%$ in 1990 . On the other hand the industrial and services sectors, both, increased in the same period. Especially the industrial sector.

From 1960 until 1990 the percentage of houses with tap water changed from $28.9 \%$ to $86.8 \%$. Those with shower and bathing tub increased from $18.6 \%$ to $81.8 \%$. Homes with sanitary equipment (indoor toilets) increased from 41.8 to $88.5 \%$. Homes with electricity increased from $40.5 \%$ to $97.7 \%$. Finally sewerage systems in 1960 were present just in 38.35 of houses and in $199090.7 \%$ of the houses had it.

Taking in to account the changes in nutrition in the Portuguese population, from the 60s to the $90 \mathrm{~s}$, the consumption of some products increased very much like milk (76 to $237 \mathrm{cal} /$ day), meat (78 to $328 \mathrm{cal} /$ day), fats (407 to 788 cal/day), sugar (209 to $350 \mathrm{cal} /$ day), eggs (14 to $30 \mathrm{cal} /$ day) and alcohol (172 to $196 \mathrm{cal} /$ day). The consumption of calories increased from 2671 to 3577 calories, between 1960 and 1990 (Barreto, 1996, 2000).

In 1972 a program of milk supply started in Portugal in elementary schools. The number of students that took advantage of this program increased from 1972 (22 000 students) to 1986 (795 327 students.

\section{SECULAR TREND IN STATURE}

\subsection{Secular Trend of Male Stature Between 1904 and 2000}

Figure 1 shows that a positive secular trend in height occurred in the Portuguese male population, between 1904 and 2000. In 1904 the mean height was $163.2 \mathrm{~cm}$ and in 2000 it was $172.13 \mathrm{~cm}$ (Table 2). The average increase was $8.93 \mathrm{~cm}$ which yields a rate of a secular increase of $0.99 \mathrm{~cm}$ per decade. Those mean increments that occurred during this period of time range from $6.72 \mathrm{~cm}$ (Santarém) to $11.54 \mathrm{~cm}$ (Bragança).

\subsection{Regional Evolution in Male Stature Between 1904 and 2000}

Table 2 and Figure 2 shows the mean values of heights for Portuguese 18-year-old males in each district of Portugal. The mean values for heights in 1904, collected from previously published data, were also represented. These data

Table 1: Evolution of some socio-demographic and health systems in Portugal between 1920 and 1990 *

\begin{tabular}{|c|c|c|c|c|c|c|c|c|}
\hline Demography & 1920 & 1930 & 1940 & 1950 & 1960 & 1970 & 1980 & 1990 \\
\hline Birth rate & 33.6 & 29.7 & 24.3 & 24.3 & 24.1 & 20.9 & 16.13 & 11.8 \\
\hline Age group $<15$ years & 32.6 & 31.9 & 31.8 & 29.2 & 29.2 & 28.5 & 25.5 & 20 \\
\hline Age group $\geq 65$ years & 5.9 & 6.2 & 6.4 & 6.9 & 8 & 9.7 & 11.5 & 13.6 \\
\hline Fecundity Index & - & 3.9 & 3.2 & 3.2 & 3.2 & 3 & 2.2 & 1.5 \\
\hline Infant mortality rate & 177 & 144 & 126 & 94.1 & 77.5 & 55.5 & 21.8 & 10.8 \\
\hline Post-neonatal mortality rate $_{4}$ & - & 95.5 & 87.5 & 62.9 & 46.77 & 31.86 & 10.46 & 3.34 \\
\hline Life expectancy - men (years) & 35.8 & 44.8 & 48.6 & 55.5 & 60.7 & 64.2 & 69.3 & 70.3 \\
\hline Life expectancy - women (years) & 40 & 49.2 & 52.8 & 60.5 & 66.4 & 70.8 & 75.3 & 77.5 \\
\hline Adult literacy (\%) & 34.6 & 39.6 & 46.4 & 58.3 & 66.9 & 74.4 & 81.4 & 89 \\
\hline \multicolumn{9}{|l|}{ Health } \\
\hline Number of physicians per 1000 & pulation & & & & 352 & 508 & 1056 & 1256 \\
\hline Maternal mortality $_{5}$ & - & 741 & 752 & 355 & 115.5 & 73.4 & 19 & 10.3 \\
\hline Born at the maternity $(\%)$ & - & - & - & - & 18.4 & 37.5 & 73.8 & 95.5 \\
\hline \multicolumn{9}{|l|}{ Economy } \\
\hline Agricultural sector & - & 48.2 & 51.4 & 49.4 & 43.3 & 39.7 & 19.4 & 10.6 \\
\hline Industrial sector & - & 17.3 & 19.7 & 23.8 & 28.7 & 40 & 38.8 & 37.2 \\
\hline Services & - & 34.5 & 28.9 & 26.8 & 28 & 20.3 & 41.8 & 50.4 \\
\hline \multicolumn{9}{|l|}{ House Conditions } \\
\hline Tap water $(\%)$ & - & - & - & - & 28.9 & 47.4 & 72.4 & 86.8 \\
\hline Shower and bathing tub $(\%)$ & - & - & - & - & 18.6 & 28.7 & 58.2 & 81.8 \\
\hline Sanitary equipment $(\%)$ & - & - & - & - & 41.8 & 58.1 & 79.1 & 88.5 \\
\hline Electricity $(\%)$ & - & - & - & - & 40.5 & 63.8 & 90.7 & 97.7 \\
\hline Sewerage systems (\%) & - & - & - & - & 38.3 & 58.1 & 68 & 90.7 \\
\hline
\end{tabular}

1 Number of births per 1000 of population, 2 Number of childrens, on average, for each women during their reproductive life (1549 years), 3 Deaths, from birth to 1 year of life per 1000 live births, 4 Deaths, from 1 month to 1 year of life per 1000 live births 5 Deaths per 100000 womens, * Adapted from Barreto $(1996,2000)$ 
Height $(\mathrm{cm})$

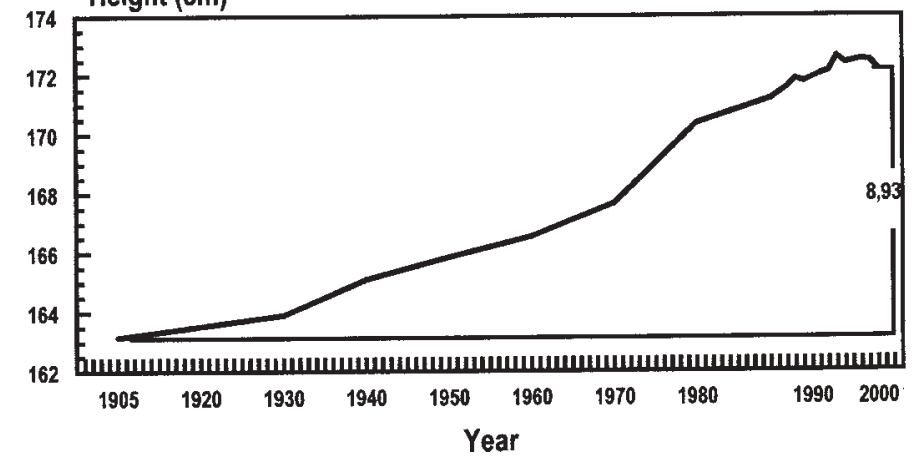

Fig. 1. Secular trend in height in the Portuguese population (1904-2000).

were also obtained from the records of the medical examination at the District Recruiting Centers of Portugal, which means that it could be compared with present data.

The one way analysis of variance for the mean height shows statistically significant differences among the localities of subject's residence in 1985 ( $\mathrm{F}=179.941, \mathrm{p} \leq 0.001)$, in $1990(\mathrm{~F}=33.42, \mathrm{p} \leq 0.001)$ and still in $2000(\mathrm{~F}=17.28, \mathrm{p} \leq 0.001)$. In 2000, the 18-year-old males from Lisboa and Braga are the tallest and those from Madeira and Coimbra the shortest. But, we should stress that, despite the significant differences that occurred in 2000 among the districts, the range between the tallest and shortest males is now much smaller $(2.29 \mathrm{~cm})$ than it was in $1904(4.7 \mathrm{~cm})$. Even in 1985 the difference between the tallest and the shortest males was very high $(4.45 \mathrm{~cm})$. It is clear, from Figure 2, that the greatest increments took place in those districts with the smallest mean height in 1904 - Castelo Branco, Guarda, Bragança, Beja and Portalegre. On the other hand, Santarém, Évora and Faro showed the lowest increments and the highest mean heights in 1904.

Table 2: Mean heights for Portuguese 18-year-old males in each district of Portugal in 1904, 1985, 1990 and 2000. One way analysis of variance $(F)$ between the 20 districts

\begin{tabular}{|c|c|c|c|c|c|c|c|c|}
\hline \multirow[b]{2}{*}{ District } & \multicolumn{2}{|c|}{ Examined in $1904+$} & \multicolumn{2}{|c|}{ Examined in 1985} & \multicolumn{2}{|c|}{ Examined in 1990} & \multicolumn{2}{|c|}{ Examined in 2000} \\
\hline & $N$ & Mean & $N$ & $M e a n \pm S D$ & $N$ & $M e a n \pm S D$ & $N$ & $M e a n \pm S D$ \\
\hline Aveiro & 3509 & 164.06 & 5404 & $168.09 \pm 6.23$ & 2208 & $170.08 \pm 6.6$ & 2882 & $171.93 \pm 6.44$ \\
\hline Beja & 1834 & 162.3 & 1597 & $169.76 \pm 6.42$ & 358 & $171.22 \pm 6.6$ & 767 & $171.42 \pm 6.12$ \\
\hline Braga & 555 & 163.95 & 7343 & $168.28 \pm 6.16$ & 3184 & $170.96 \pm 6.24$ & 5015 & $172.67 \pm 6.3$ \\
\hline Bragança & 210 & 160.3 & 1647 & $168.71 \pm 6.06$ & 719 & $170.87 \pm 6.37$ & 736 & $171.84 \pm 6.3$ \\
\hline C. Branco & 1671 & 160.4 & 1725 & $168.04 \pm 6.1$ & 740 & $170.98 \pm 6.31$ & 855 & $171.31 \pm 6.4$ \\
\hline Coimbra & 4983 & 162.58 & 3305 & $168.55 \pm 6.39$ & 1530 & $171.08 \pm 6.58$ & 984 & $171.31 \pm 6.4$ \\
\hline Évora & 995 & 164.04 & 1405 & $170.15 \pm 6.24$ & 425 & $172.2 \pm 6.33$ & 840 & $171.72 \pm 6.62$ \\
\hline Faro & 2625 & 165 & 2000 & $170.37 \pm 6.4$ & 681 & $171.93 \pm 6.41$ & 1255 & $172.59 \pm 6.43$ \\
\hline Guarda & 378 & 160.5 & 1630 & $167.13 \pm 6.36$ & 603 & $169.69 \pm 5.54$ & 827 & $171.46 \pm 6.15$ \\
\hline Leiria & 410 & 162.1 & 3251 & $168.0 \pm 6.15$ & 1377 & $170.56 \pm 6.35$ & 1820 & $171.31 \pm 6.46$ \\
\hline Lisboa & 1319 & 164.2 & 12860 & $171.58 \pm 6.52$ & 5529 & $172.75 \pm 6.36$ & 6395 & $172.79 \pm 6.47$ \\
\hline Portalegre & 410 & 162.3 & 1167 & $169.51 \pm 6.28$ & 370 & $171.52 \pm 6.17$ & 563 & $172.59 \pm 6.54$ \\
\hline Porto & 1213 & 163.8 & 14346 & $168.97 \pm 6.4$ & 6069 & $171.56 \pm 6.37$ & 8092 & $172.25 \pm 6.31$ \\
\hline Santarém & 1050 & 164.7 & 3307 & $169.13 \pm 6.16$ & 1411 & $171.32 \pm 6.28$ & 1722 & $171.42 \pm 6.09$ \\
\hline Setúbal & 450 & 164.48 & 2840 & $171.34 \pm 6.23$ & 1137 & $173.09 \pm 6.01$ & 1453 & $172.17 \pm 6.4$ \\
\hline V. Castelo & 1972 & 163.88 & 2127 & $168.71 \pm 6.22$ & 884 & $171.57 \pm 6.48$ & 1256 & $172.05 \pm 6.25$ \\
\hline Vila Real & 2095 & 163.3 & 2663 & $168.11 \pm 6.24$ & 1029 & $171.19 \pm 6.27$ & 1423 & $171.98 \pm 6.4$ \\
\hline Viseu & 2104 & 162.58 & 4138 & $167.52 \pm 6.25$ & 1537 & $169.77 \pm 6.51$ & 2281 & $171.84 \pm 6.26$ \\
\hline Açores & - & - & 1801 & $169.58 \pm 6.41$ & 1573 & $170.07 \pm 6.69$ & 1340 & $172.96 \pm 6.43$ \\
\hline Madeira & - & - & 2091 & $169.48 \pm 6.53$ & 1807 & $170.97 \pm 6.35$ & 1078 & $170.67 \pm 6.3$ \\
\hline Total & 27783 & 163.2 & 76647 & $169.24 \pm 6.46$ & 33270 & $171.38 \pm 6.45$ & 42584 & $172.13 \pm 6.38$ \\
\hline $\mathrm{F}$ & & & & $\mathrm{F}=179.941 *$ & & $\mathrm{~F}=33.42 *$ & & $\mathrm{~F}=17.28 *$ \\
\hline
\end{tabular}




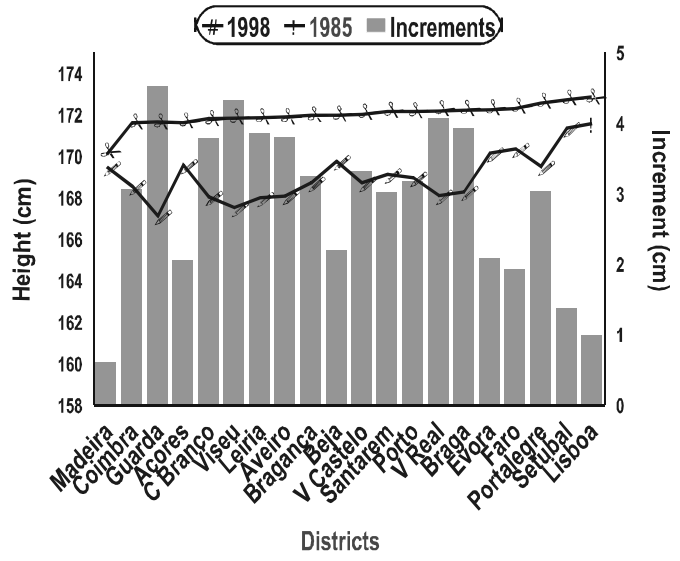

Fig. 2. Mean height of Portuguese 18-year-old males, in each District of Portugal, in 1904 and 2000.

\subsection{Secular Changes in Age at Menarche in the Portuguese Population Between 1880-1980}

Figure 3 shows the secular trend in age at menarche in Portugal. Previous data published by other authors was considered. It is clear from Figure 3 that a decrease in the mean age at menarche occurred in the Portuguese population. Girls born in the decade 1880-1890 had a mean age at menarche of 15 years and those who were born in 1970-1980 had a median age at menarche of 12.03 years.

\section{CONCLUSIONS}

This study of secular trend in Portugal has shown that a positive increment in height occurred in Portuguese 18-year-old males between 1904 and 2000, and a secular trend in the age at menarche, towards an earliest age, also took place.

The overall increase in height, in this period, was $8.93 \mathrm{~cm}$, which yields a rate of $0.99 \mathrm{~cm}$ per decade. This increment is similar to the average rates of secular increase that took place during this century in most Western and industrialized countries. The secular increase in adult height varied between 0.3 and $3.0 \mathrm{~cm} /$ decade (Eveleth and Tanner, 1990, Hauspie et al., 1996). In 2000, the average final height was $172.13 \mathrm{~cm}$. Despite this increase, the Portuguese are the shortest in Europe. The most recent published data indicate mean males heights of: Spain - $173.8 \mathrm{~cm}$ (Rebato, 1998); France - $174.9 \mathrm{~cm}$ (Pineau, 1993); Belgium - 176.8 $\mathrm{cm}$ (Vercauteren, 1993); Bulgaria - $173.6 \mathrm{~cm}$ (Stoev and Yordanov, 1998); Czech Republic $-178.84 \mathrm{~cm}$ (Vignerová and Bláha, 1998); Austria - 177.5 (Weber et al., 1995); England - $175.7 \mathrm{~cm}$ (Rosenbaum et al., 1985); Poland - $176.86 \mathrm{~cm}$ (Bielicki and Waliszk, 1991); Greece - $177.6 \mathrm{~cm}$ (Manolis et al., 1995); Hungary - $178.5 \mathrm{~cm}$ (Gyenis, 1997); Sweden - 179.5 $\mathrm{cm}$ (Tuvemo et al., 1999) and Netherlands - $184 \mathrm{~cm}$ (Fredriks et al., 2000).

As in almost all the other countries, the rate of secular increase was not constant during the overall period. Taking into account our results, for 2000, and those published by Sobral (1990) just for the same Districts that both of us analyzed (Lisboa, Setúbal, Évora and Beja for 1930-1980), we obtain the following rates: $1.21 \mathrm{~cm}$ for $1930-$ $40,0.74 \mathrm{~cm}$ for $1940-50,0.7 \mathrm{~cm}$ for $1950-60,1.11 \mathrm{~cm}$ for $1960-70,2.7 \mathrm{~cm}$ for $1970-80,1.68 \mathrm{~cm}$ for $1980-$



Fig. 3. Secular trend in age at menarche in the Portuguese population (1880-1980). 
1990 and $0.75 \mathrm{~cm}$ for $1990-2000$. From these values it is clear that the greatest rates occurred between the 1960s and the 1970s.

The overall positive secular trend in height in the Portuguese population, and the greatest increase in adult height in those districts that were the shortest in 1904, represents a general improvement in living conditions that occurred in Portugal after the 1970s. Castelo Branco, Guarda, Bragança and Portalegre, some of the more inland districts, were the shortest in 1904 but had the highest increments between 19042000, reaching values of $10.91 \mathrm{~cm}, 10.96 \mathrm{~cm}, 11.54$ $\mathrm{cm}$ and $10.29 \mathrm{~cm}$ respectively. On the other hand, Santarém, Faro and Evora were the tallest in 1904 and had the lowest increments between that period of time with values of $6.72 \mathrm{~cm}, 7.59 \mathrm{~cm}$ and $7.68 \mathrm{~cm}$ respectively. The first ones had also the highest post-neonatal mortality rates in 1930, respectively $81.75,116.05$ and 96.11 . The last ones had lower post-neonatal mortality rates with $72.13,81$ and 90.23 , respectively. This probably means that the short heights of the first group were related to worst living conditions of their districts, according to post-neonatal mortality values.

A secular trend in the age at menarche, towards an earliest age, occurred in the Portuguese population. Published data showed that in the birth decade of the 1880-90 the mean age was 15 years and in 1980 declined to a value of 12.03 years.

Socioeconomic factors cannot influence growth and sexual maturation directly, but have to act through biological factors such as nutrition and infection, both of which may influence height and age at menarche (Sandberg and Steckel, 1987, Floud et al., 1990). The increase in mean stature and the decrease in mean menarcheal age represent a general improvement in the living conditions that occurred in Portugal after the 1970s. The Portuguese nutritional pattern, the health care system, the economy and even in housing conditions changed between 1960 and 1997 (Barreto, 1996; Barreto, 2000).

The Portuguese nutrition pattern change deeply between 1960 and 1997. Consumption of some products, such as milk, meat, eggs, sugar, proteins and fats, increased considerably. In other populations like Italy, Ullizi and Terrenato (1982) stressed the importance of these dietary components on the secular trend on Italian conscripts born from 1874 and 1960.
Another example is the Japanese population. Takahashi (1984) has linked the secular trend in height in Japan to the consumption of milk, which has risen steeply since the World War II and concluded that milk consumption among the younger generation was one of the most important causes of the acceleration of growth in height.

The Portuguese health system has made great improvements, mainly after the 1940s and 1970s, as confirmed by the decrease in post-neonatal mortality values in all the districts, the increase in life expectancy and the specific increase in other health care characteristics such as the number of physicians per 1000 population, or the percentage of newborn that were born at the maternity. The post-neonatal mortality rate, is regarded as a sensitive indicator of infant health for a population (Kessel, 1990). Infant nutritional status and the prevalence of infections are regarded as the most important determinants of post-neonatal mortality (Stembera, 1990). These results are in a good agreement with those obtained by Schmidt et al. (1995) who found that, among several European countries, the general trend is that height increases toward a maximum when post-neonatal mortality approaches zero. They speculate that adult height in the middle and southern European countries will continue to increase for approximately two decades after post-neonatal mortality has reached a low and stable level at about 3-5 per 1000 deliveries. Viewed in this perspective, and taking into account the post-neonatal mortality values that still exists in 1990 in the districts analysed, we could still expect an increase in the mean height of the adult Portuguese population in the future decades because some of the districts still present an high rate such as Bragança (8.03), Guarda (5.89), Madeira (5.92), Viana do Castelo (5.93), Castelo Branco (4.73), Vila Real (5.93) and Viseu (4.68). Those Districts were also in the group of those with the shortest mean heights in 2000.

The heights of recruits reflect the nutritional status of a population some 15-20 years before. Many studies suggested that adverse environmental factors have their strongest effects during childhood (Cole, 2000; Schmidt et al., 1995; Tanner, 1992). The males of the analysed data were born between 1966-1982, and the adolescent girls were born between 1970-80. For both cases, if their birth decade is paired 
with the socioeconomic changes described, namely those concerning nutrition, health system and economic development, they were in their childhood or adolescence. This means that they were the first ones to take advantage of those improvements in the living conditions, especially to be able to afford better nutrition, a better health care system, a better economy, in general a more comfortable way of life conditions. Similar results occurred in almost all the European countries such as Spain (Prado, 1990), The Netherlands (van Wieringen, 1986), Germany (Bremerhaven) (Ostersehlt and Danker-Hopfe, 1991), the Czeck Republic (Prokopec, 1989) and Hungary (Szeged) (Eiben, 1994). Some studies provide evidence of a stagnation in age at menarche over the past decade(s), e.g. in Belgium (Vercauteren and Susanne, 1985) and Norway (Brundtland et al.,1980). Areversal of this trend has been observed in Sweden (Stockholm) (Lindgren and Hauspie, 1989), Hungary (Kormend) (Eiben, 1994) and Croatia (Zagreb) (Prebeg 1995). From these studies it seems that the age at menarche is still decreasing in many countries, but has reached a plateau or even reversed its trend in others. More studies are needed to evaluate what is happening with the Portuguese population.

It is difficult to define which indicator would be the most representative of environmental improvement because they are always to intricate and they are the result of all the social and economic changes of the Portuguese society in the last decades but, in this country, we can make the hypothesis that the health system had the strongest effect and must be the best "mirror" of the Portuguese living conditions.

In summary these results demonstrated that a positive secular increase in adult height is occurring, like that which took place over all the European countries, and is still continuing is several countries. On the other hand, considering the decrease in age at menarche in the Portuguese adolescents, from 1880-90 to 1980, we could expect that a plateau was reached. Great socio-economic changes took place in Portugal, especially in terms of nutrition and health system. We could conclude that these improvements are reflected in the increase of the mean adult heights and in the decrease of age at menarche.

\section{REFERENCES}

Apraiz, A. G.: Influence of family size and birth order on menarcheal age of girls from Bilbao City (Biscay,
Basque Country). Am. J. Hum. Biol., 11: 779-783 (1999)

Barreto, A.: A Situação Social em Portugal, 1960-1995. Instituto de Ciências Sociais, Universidade de Lisboa, Lisboa (1996)

Barreto, A.: A Situação Social em Portugal, 1960-1999. Volume II. Instituto de Ciências Sociais, Universidade de Lisboa, Lisboa (2000).

Bielicki, T. and Waliszko, H.: Urbanization-dependent gradients in stature among Polish conscripts in 1976 and 1986. Am. J. Hum. Biol., 3: 419-424 (1991).

Billewicz, W. Z., Fellowes, H. M. and Thomson, A. M.: Menarche in Newcastle upon Tyne girls. Ann. Hum. Biol., 8: 313-320 (1981).

Bodzsár, É. B. and Susanne, C.: Patterns of secular change of growth and development, pp.5-26, In Secular Growth Changes in Europe. E. B. Bodzsár and C. Susanne (Eds). Eotvos University Press, Budapeste (1998).

Brundtland, G. H., Liestol, K. and Walloe, L.: Height, Weight and Menarcheal Age of Oslo Schoolchildren During Last 60 Years. Ann. Hum. Biol., 7: 307-322 (1980).

Cameron, N. and Nadgdee, I.: Menarcheal age in two generations of South African Indians. Ann. Hum. Biol., 23: 113-119 (1996)

Chinn, S., Rona, R. J. and Price, C. E.: The secular trend in height of primary school children in England and Scotland 1972-79 and 1979-86. Ann. Hum. Biol., 16: 387-395 (1989)

Cole, T. J.: Secular trends in growth. Proc. Nut. Soc., 59: 317-324 (2000).

Eiben, O.: The Kormend growth study: data to secular growth changes in Hungary. Auxology 94 - Children and youth at the end of the 20th century. Budapest: Hum. Budap., 25: 205-219 (1994).

Eveleth, P. B. and Tanner, J. M.: Worldwide variation in Human Growth. Cambridge University Press., Cambridge, 2th edition (1990).

Floud, R., Wachter, K., and Gregory, A.: Height, Health and History. Cambridge University Press, Cambridge: (1990).

Fredriks, A. M., Van Buuren, S., Burgmeijer, R. J. F., Meulmeester, J. F., Beuker, R. J., Brugman, E., Roede, M. J., Verloove-Vanhorick, S. P. and Wit, J-M.: Continuing positive secular growth change in the Netherlands 1955-1997. Ped. Res., 47: 316-323 (2000).

Gyenis, G.: Continuing positive growth changes in height and weight of Hungarian university students. Ann. Hum. Biol., 24: 475-479 (1997).

Hauspie, R.C., Vercauteren, M., and Susanne, C.: Secular changes in growth. Horm. Res., 45(supp 2): 8-17 (1996).

Keizer-Schrama, S.M.P.F.: Trends in pubertal development in Europe. Huma. Repro., 7: 287-291 (2001).

Kessel, S.S.: Postneonatal mortality: a performance indicator of the child health care system. Pediatrics, 86: 1107-1111 (1990).

Lacerda, J.: Estatura do Português Adulto. Dissertação para a cadeira de Antropologia (Manuscrito). Universidade de Coimbra, Coimbra (1904).

Lindgren, G. W. and Hauspie, R. C.: Heights and weights of Swedish school children born 1955 and 1967. Ann. Hum. Biol., 16:397-406 (1989). 
Manolis, S., Neroutsos, A. and Zafeiratos, C.: Secular changes in body formation of Greek students. Hum. Evol., 10: 199-204 (1995)

Ostersehlt, D. and Danker-Hopfe, H.: Changes in age at menarche in Germany: Evidence for a continuing decline. Am. J. Hum. Biol., 3: 647-654 (1991).

Pineau, J. C.: La stature en France depuis un siécle: évolution générale et régionale. Bull. Mém. Soc. d'Anthrop. Paris, 5: 257-268 (1993).

Prado, C.: Secular changes in height, weight and menarche in Spain during the last three decades (1955-1985). J. Hum. Ecol., 1: 21-29 (1990).

Prebeg, Z.: Variations in menarcheal age of school girls in Croatia, in Essays on auxology presented to James Mourilyan Tanner. Edited by R. Hauspie, Lindgren, G.; Falkner, F., pp. 224-231. Castlemead Publications, Welwyn Garden City: (1995).

Programa das Nações Unidas para o Desenvolvimento (PNUD): Relatório Do Desenvolvimento Humano 2001. Trinova Editora, Lisboa (2001).

Prokopec, M.: Growth surveys and growth surveillance in Czechoslovakia. pp. 121-131. In: Auxology 98 Perspectives in the Science of Growth and Development. J. M. Tanner (Ed.), Smith-Gordon, Nishimura (1989).

Rebato, E.: The studies on secular trend in Spain: a review, pp.297-317, In: Secular Growth Changes in Europe. É. B. Bodzsár and C. Susanne (Eds.). Eotvos University Press, Budapeste (1998).

Rosenbaum, S., Skinner, R. K., Knight, I. B. and Garrow, J. S.: A survey of heights and weights of adults in Great Britain. Ann. Hum. Biol., 12: 115-127 (1985).

Sánchez-Andrés, A.: Genetic and environment factors affecting menarcheal age in Spanish women. Anthrop. Anz., 55: 69-78 (1997).

Sandberg, L.G. and Steckel, R. H.: Heights and economic history: the Swedish case. Ann. Hum. Biol.,14: 1010110 (1987).

Schmidt, I. M., Jorgensen, M. H. and Michaelsen, K. F.: Height of conscripts in Europe: is postneonatal mortality a predictor? Ann. Hum. Biol., 22: 57-67 (1995).

Sobral, F.: Secular Changes in Stature in Southern Portugal between 1930 and 1980 According to Conscript Data. Hum. Biol., 62: 491-504 (1990).

Stembera, Z. Prospects for heights infant survival World Health Forum, 11: 78-84 (1990).

Stoev, R. and Yordanov, Y.: Secular trend in Bulgaria. In Secular Growth Changes in Europe, pp. 65-73, In: Secular Growth Changes in Europe. E. B. Bodzsár and C. Susanne (Eds.). Eotvos University Press, Budapeste (1998).

Takahashi, E.: Secular trend in milk consumption and growth in Japan. Hum. Biol., 56: 427-437 (1984).

Tanner, J. M.: Growth as a mirror of the conditions of society: secular trends and classifications, pp. 3-34, In: Human Growth : A Multidisciplinary Review. A. Demirjan and M. Brauit Dubuc (Eds.). Taylor and Francis, New York (1986)

Tanner, J. M.: Growth as a Measure of the Nutritional and Hygienic Status of a Population. Horm. Res., 38(suppl.):106-115 (1992).

Tuvemo, T., Jonsson, B. and Persson, I.: Intellectual and physical performance and morbidity in relation to height in a cohort of 18-year-old Swedish conscripts. Horm. Res., 52: 186-191 (1999).

Ulizzi, L. and Terrenato, L.: A comparison between the secular trends of stature and some socio-economic factors in Italy. J. Hum. Evo. 11: 715-720 (1982).

van Wieringen, J. C.: Secular growth changes, pp. 307331, In: Human Growth. F. Falkner and J.M. Tanner (Eds.). Plenum Press, New York (1986).

Vercauteren, M.: Croissance, facteurs socio-familieux et évolution séculaire. Bull. Mém. Soc. d'Anthopol. Paris, 5: 85-92 (1993).

Vercauteren, M. and Susanne, C.: The secular trend of height and menarche in Blegium: are there any signs of a future stop? Eur. J. Ped., 144: 306-309 (1985).

Vignerová, J. and Bláha, P.: The growth of the Czech child during the past 40 years, pp. 93-107, In Secular Growth Changes in Europe. E. B. Bodzsár and C. Susanne (Eds.). Eotvos University Press, Budapeste (1998).

Weber, G., Seidler, H., Wilfing, H. and Hauser, G.: Secular change in height in Austria: an effect of population stratification? Ann. Hum. Biol., 22: 277-288 (1995). 